\title{
La Orden de Venus en el Comentario de Hernán Núñez. Dignidad humana y conducta amorosa
}

\author{
Antonio CORTIJO OCAÑA \\ University of California
}

\section{RESUMEN}

Este trabajo presenta un análisis del Comentario $(1499,1505)$ de Hernán Núñez de Toledo al Laberinto de Fortuna de Juan de Mena. En particular, se analiza el concepto humanista del amor en el contexto de la construcción de un sujeto individual, miembro de la comunidad política y social.

Palabras clave: Humanismo, Hernàn Núñez de Toledo, Juan de Mena, Laberinto de Fortuna, Glosa a las Trescientas.

\begin{abstract}
This paper analyzes Hernán Núñez de Toledo's Comentario (1499, 1505), a humanist analysis of Juan de Mena's Laberinto de Fortuna. In particular, the author focuses on Núñez de Toledo's ideas on love in the context of Humanism's construction of a philosophy of the subject (both as a pyschological construct and as a member of the political and social community).
\end{abstract}

Keywords: Humanismo, Hernán Núñez de Toledo, Juan de Mena, Laberinto de Fortuna, Glosa a las Trescientas.

El tema del presente trabajo será la el análisis del fenómeno amoroso como esencial para la definición y construcción de sentido de la vida humana que realiza Hernán Núñez de Toledo, el comendador griego, en su análisis/comentario a las coplas C-CXV del Laberinto de Fortuna, de Juan de Mena, dentro de su magna obra Comentario a las Trescientas de 1499 (1505). Este análisis constituye su exégesis del llamado Círculo de Venus o Tercera orden, donde se encuentran los caídos en desgracia por el vicio de la lujuria.

Venidos a Venus vi en grado especial

los que en el fuego de su juventud 
hazen el vicio ser sancta virtud por el sacramento matrimonial; debaxo de aquéstos, vi grand general de muchos linages caýdos en mengua, que no sabe cómo se diga mi lengua tantas especies y formas de mal. (copla C)

Se da en él repaso al conjunto de temas, topoi e ideas que sobre el amor son paradigmáticos en la literatura medieval, en particular la de los siglos XIV y XV, con sus dos ejes o influencias centrales, la de Ovidio-Andreas Capellanus-amor cortés (A. Cortijo [2001], P. Cátedra, K. Whinnom) y la de la reflexión psico-filosófica de la escolástica (A. G. Weiler). Todo se hace girar en torno al análisis del ejemplo que sirve de corolario final del círculo entero, la historia de Macías el Enamorado, que sirve a Hernán Núñez para resumir sus ideas (y las de sus fuentes) sobre el amor. Salvando ciertas distancias, ciertas estéticas y eliminando algunas referencias ya trasnochadas para el siglo XVI (patrísticas en su mayor parte), sirve igualmente de introducción a actitudes y temas/topoi amorosos que habrán de desarrollarse apenas unas décadas después de la escritura de dicha obra, dentro de la llamada poética petrarquista (I. Navarrete, G. Caravaggi, J. I. Díez Fernández).

Hernán Núñez de Toledo (ca. 1470-1553) es ante todo humanista y preceptor, comentarista literario, erudito y enseñante (ver T. Jiménez Calvente [2001 y 2002]; H. Nader; B. Weinberg). Su labor de comentarista en la Glosa se realiza dentro de un contexto más amplio que el del simple comentario a un poema castellano. Quiere el de Toledo realizar un magno programa de presentación práctica del ideal humanista, de conjunción de los saberes pagano y cristiano, de ejemplificación de un ideal de conocimiento y aplicación del saber para el ejercicio práctico de la virtus personal y social, a la par que religiosa. Igualmente, quiere rivalizar como nadie antes que él con el humanismo italiano y su reivindicación de la relevancia/importancia de la lengua y literatura vernáculas. En un camino ascendente que va del accessus a un texto a su toma como excusa para presentar el saber como conducente a un modus vivendi, Núñez propone un sistema en esencia totalizador que lleva de la geografía y cosmografía a la reflexión teológico-bíblica, pasando por un conjunto de disciplinas subsidiarias que se centran en res y verba, verba y res y que abordan casi todos los saberes del momento: historia, poética, mitología clásica, astronomía, literaturas griega y latina, etc. Junto a ello también se demuestra conocedor de la historia contemporánea española, así como de las obras literarias en vernáculo. En este sistema los pilares básicos están constituidos por un andamiaje centrado en el hombre y su constitución como ser virtuoso, que debe cumplir la función psicológica central de conocimiento de sí mismo y del mundo físico que le rodea (física, geografía, etc.) para ejercitar su humanidad en sociedad (no en aislamiento); y un andamiaje representado por un modus dicendi, un ornato verbal que asimila el contenido de lo dicho a un estilo de decir, que alcanza su mayor dignidad no solo en la conducta 
(moral) o aplicación práctica de dicho contenido sino y a través del modo como se explica y expresa la doctrina que conduce a la conducta. Una imbricación, en suma, de expresión y racionalidad o, si se quiere, una asunción de la expresión verbal como parte de la esencia humana que otorga al hombre su propia dignidad.

Dentro de su comentario, el círculo tercero (o "tercera orden, de Venus") se centra de preferencia (no exclusivamente) en el tratamiento del amor como fenómeno anormal o insano, dando preferencia a una especie de casuística de lo que podría denominarse enfermedad amorosa, desequilibrios causados por el amor, conductas reprobables moralmente como consecuencia de una cierta práctica amorosa. En esto no hay apenas desviación del modelo de Dante en su Divina Comedia, donde tanto en Infierno como en Purgatorio moran seres que se han comportado con exceso (lujurioso) en cuanto al amor. Todo ello, hacia el final del poema, queda entreverado de una cierta complicidad con el sufridor de amor, o al menos con un tributo a la naturalidad amorosa, lo que hasta cierto punto puede pensarse que mitiga la condena moral de la reprobatio amoris. Ello da paso a un homenaje/reconvención/aviso a propósito de la figura de Macías, el vate que había ya para esta época quedado aupado a una categoría paradigmática como amador perfecto, suma de amadores, ejemplo castellano de amador que oponer o con el que rivalizar con los franceses y catalanes que en sus respectivas poesías quedaran como modelos de amor (A. Cortijo [2001]). Y se remata con unas consideraciones, a modo de apelación al rey, sobre la importancia para la salud del reino de que el monarca vele, con justicia y clemencia, por la salux amorosa del mismo.

Hernán Núñez está dedicado en cuerpo y alma a su tarea docente y de comentario e interpretación. Y su saber no está regido por un prurito de erudición o de utilización exhaustiva de fuentes (muchas recién descubiertas o recién editadas) clásicas grecolatinas. Aun siendo todo ello, es primero y ante todo explicación de la esencia del hombre a través del análisis (y enseñanza) de algunos de los frutos intelectuales más conspicuos del intelecto humano, cuyas letras no solo proporcionan información, sino placer estético y enseñanza sobre el contenido de la moralidad humana para su aplicación práctica. Dentro de este que puede denominarse gran proyecto humanista, en su Comentario es raro que los grandes temas de la reflexión filosófica no estén guiados por el afán de Núñez de proporcionar a su lector una magna lectio que recoja in toto todos los aspectos de la materia a tratar. Éste es, una vez más, el caso del tema del amor en su exposición del círculo de Venus. Intelecto, Amor, Relación con la Divinidad son tres facetas que tocan de modo especial a la personalidad humana. Y las tres, curiosamente, están imbricadas de un modo especial, como si fueran manifestación de la esencia relacional del ser humano, esa que en términos griegos se puede denominar eros, en sentido lato. La exposición de Núñez avanzará paso a paso, construyendo un edificio (metáfora querida al toledano) que solo se podrá ver concluido al final de la exposición. Empecemos por la senda por que nos quiere llevar Hernán Núñez. 
Las coplas C y CI definen el amor como conducta viciosa, vitium, cuando se sale de los límites que podrían considerarse normales, siempre y cuando dicho comportamiento esté precedido o regido por el libre asentimiento de la voluntad. Esta conducta, en términos clásicos, y escolásticos de añadidura, es un furor, una pasión consumidora, destructora de la racionalidad, eje del ser humano sintiente y pensante, axis sobre el que se asienta, en buen sentir humanista, la dignidad humana. Pertenecen a esta categoría los que prestan asentimiento a su lujuria, a su deseo pasional, del que son especialmente susceptibles los jóvenes:

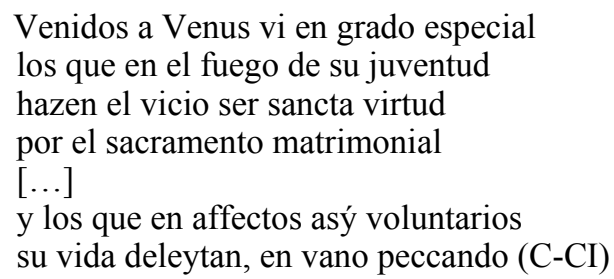

A este grupo, dice Núñez, pertenecen los que llevan el vicio a un extremo reprobable moralmente, como los "adúlteros y fornicarios", los "incestuosos" y los "maculados del crimen nefando" (CI), junto a los que ejercitan el bestialismo (CIV). A los dos primeros mueve la "luxuria", los segundos actúan "contra natura". Sobre los tres se cierne no sólo una reprobatio moral, sino hasta las leyes religiosas y civiles. En el mismo grupo, porque facilitan la actuación de los otros (además de porque pueden usar de prácticas mágicas que captan la voluntad) debe incluirse a los "alcahuetes". En todos estos casos la conducta de los "criminosos" no tiene solo consecuencias de índole individual y personal. Su furor amatorio, su ejercicio voluntario de la pasión amorosa tiene consecuencias sociales que salen fuera del individuo. A este aspecto de la repercusión social de la lujuria se refiere el comentario de 101a et ss. La referencia a Levítico y condena véterotestamentaria de adúlteros, fornicarios, incestuosos no se hace solo desde un punto de vista moral, que se sobreentiende, sino de preferencia desde un punto de vista legal. No es la iustitia Dei la que impone la reprobatio, sino es la iustitia hominum la que pune estos crímenes como atentatorios contra la fábrica social.

Las historias de casos griegos que siguen, y que se exponen en el comentario a la copla 101g-104h, sirven de ejemplo de la repercusión extra-individual del individualismo. En su mayoría pertenecen a la historia griega (Mirra, Helena, Filomena y Progne, Centauros, etc.) y tienen como fuente varios autores, como Estrabón o la Historia de Alejandro, aunque de preferencia provienen de Ovidio y sus Metamorfosis. La quies, la paz o equilibrio (que, como áurea medida debe regir como ideal la conducta del inviduo, alejado de los extremos que incitan a un des-equilibrio de la racionalidad) es también un ideal político, un desiderato social. La salud social se logra con la vida pacífica, y esta quies, en el caso griego, se vio aniquilada por pasiones desenfrenadas que condujeron a conflictos armados, rompiendo así, a nivel político-militar, la vida pacífica de la polis. Repetidamente Núñez califica las 
conductas de quienes ejercieron estos vicios como contra las leyes humanas y divinas, cubriendo con ello todos los órdenes posibles del ordo naturalis, ordo civilis y ordo religiosus, todos los planos en construye yuxtaponiéndolos y bifurcádolos la conducta humana y sus motivaciones, causas y efectos: la del individuo aislado y el individuo en sociedad. Esta irracionalidad política que atenta contra el orden pacífico social encuentra su paralelo en el bestialismo de Pasífae (CIV), que, al juntarse con "una animalia bruta como es el toro", cometió un acto "muy torpe y obsceno". Este clímax de la conducta irracional se entiende como la relación con un animal no racional. Se llega así al colmo no solo de la torpeza moral sino del rebajamiento sumo de la humanidad al privarse voluntaria y conscientemente de lo que otorga al ser humano su esencia suprema: la racionalidad.

Es precisamente sobre este punto, el de la racionalidad, unida a la voluntad (el otro pilar de la conducta moral humana y de la dignidad del hombre como creación divina), sobre el que se centra el ejemplo de Scylla que se comenta en 104h. El personaje central del commentarium es Circe, "una mujer benéfica y hechizera." La magia para Núñez supone una conducta nefanda, viciosa, reprobable por querer captar la voluntad humana con intención de usurpar la libertad del ser humano como libertad volitiva. Si algunos de los crímenes amorosos descritos por Mena/Núñez son contra natura y pervierten un ordo naturalis creado por la divinidad, es también contra natura ejercer un papel divino y trastocar el ordo naturalis que concibió al ser humano como individuo racional, cuya esencia está en permanecer en el escalafón como superior en el orden de la creación precisamente por su capacidad de razonar y de decidir tras el ejercicio de la prudentia. Bestialismo y hechicería, en suma, no están tan alejados el uno del otro como pareciera. Mediante la aniquilación de la voluntad se llega a rebajar al ser humano a la categoría de animalia, movida solo por el placer, la búsqueda del deleite, la pasión y el instinto. Mas no debe olvidarse que la magia (en el amor cuando menos) para Núñez no ha de tener efecto alguno sobre la voluntad. En el comentario a 110ab, y con base en De arte amandi de Ovidio, se encarga de recordar que en el amor solo obtiene triunfo la conducta basada en el hacerse digno del amor, poniendo el énfasis en la voluntad y dignidad del individuo que sujeta las riendas de su propio destino:

Engáñase el que en el amor usa hechizos y da lo que arranca de la frente del potrico tierno: no causarán el amor ni las yervas de Medea ni las ponçoñas de los marsos mezcladas con palabras de encantaciones, porque si esto aprovechasse Medea pudiera retener en su amor a su marido Jasón, y Circe a Ulyxes. No traen ningún fruto los philtros que son brevajos ponçoñosos que las moças dan a sus enamorados, porque éstos antes tornan locos a los que los beven. Sean las tales maldades alexos, y para que seas amado procura de hazerte digno dello, lo qual no sólo da la hermosura.

Con el comentario a la copla CV, la historia de Macías, se alcanza un cenit en el análisis del fenómeno amoroso. Dicho episodio se privilegia no solo temática sino estructuralmente. En el conjunto de las 16 coplas que componen el canto de la orden tercera de Venus, las CV-CVIII abordan dicho tema y se sitúan en un puesto central, a 
modo de bisagra, de manera semejante a como Montemayor compondrá su Diana sobre la llegada, a mitad de la obra, al palacio de la sabia Felicia, creando así un antes y un después que se explica a partir de dicho centro. El tema Macías además es el que más amplio lugar ocupa en el comentario de la Orden tercera, con mucha diferencia. Macías, comienza Hernán Núñez, es el ídolo o modelo de "los que siguen la malicia del amor". Pero este malum será analizado por Núñez con mucha precacución, pues la complejidad de la historia así lo requiere. Macías se enamoró de una doncella del maestre de Calatrava, "doncella de grand hermosura". Desposada la dama (no con Macías), el poeta/amador "no se pudo retraer de la amar". Macías se vio incapacitado en su voluntad, impotente parece decir el comentarista, ante un sentimiento superior a sus fuerzas, ageno a su control. Este enfurecimiento amoroso es el responsable de haber creado una dementia en el amante, sin duda una pérdida de su capacidad racional. Macías, en suma, ha visto su deleite convertido en llanto ("y vimos que estava llorando los días / en que de su vida tomó fin amando," 105cd). La canción misma del poeta, "Amores me dieron corona de amores," supone un sabio resumen de este sentir. En la copla CVI Núñez parafrasea los versos de la siguiente manera:

Pues que yo me vi en las passiones que agora vosotros padecéis, creedme amadores, como a experimentado y apartaos del amor. (106g)

La canción, a su vez, expresa en dolorido sentir un juego de opuestos, de conceptos antitéticos moderados por un patetismo exacerbado:

Vencen el seso los dulces errores, mas no duran siempre, segund luego aplazen, pues me hizieron del mal que vos hazen: sabed al amor desamar, amadores. (105eh)

A un disfrute temporal y pasajero se opone la condena eterna. Al gusto o deleite del amor se opone el dolor del mal. La dulzura, aunque errada, solo redunda en desamor. La siguiente copla, CVII, expresa este mismo concepto en alocución ficticia de Macías a los amadores que pudieren estar tentados de seguir sus pasos:
Copla cvii
Huyd un peligro tan apasionado, sabed ser alegres, dexad de ser tristes, sabed deservir a quien tanto servistes, a otro que amores dad vuestro cuydado; los quales, si diessen por un ygual grado sus pocos plazeres segund su dolor, no se quexaría ningún amador, ni desesperara ningund desamado.

Núñez comenta sobre la misma que lo que Macías quiere decir a los amadores es que se aparten del amor, "porque es una passión que trae consigo muchos peligros". 
De hecho el peligro del amor radica en el extrañamiento de sí mismo, la pérdida de la personalidad y por ende la desaparición de la esencia humana. Summum periculum, pues, mayor que el cual no puede concebirse nada. "Entre las notables sentencias de Catón Censorino", amonesta Núñez, "era una que dezían los enamorados vivir en cuerpos ajenos". Porque si el amor, fruto del enamoramiento, espera un galardón y un deleite, llevado de una pasión fortísima, no es menos cierto que a la postre el deleite se torna pasajero, la pasión enardecida se troca en pati (sufrimiento), la esperanza en condena. Perdido el equilibrio, superado el medio que sostiene el edificio del ser humano, la quies se transforma en bellum, el enardecimiento en enfurecimiento, el amor en dolor, la racionalidad en locura, el ser humano en "animalia fiera". De ahí que quien se extraña de sí mismo y no se puede retraher de amar se vea metafórica y realmente "ciego" (CIX) y "preso del amor" (108a), pues, incluso aunque quiera "refrenarse," no puede. Y no es casualidad que del mismo modo que el Siervo libre de Amor de Juan Rodríguez del Padrón acabe en su tercera parte con la aparición de Sindéresis, prudentia rationalis (Folger), que quiere restablecer al protagonista de la obra en el dominio de sí mismo, Núñez se acomode al sentir de la escolástica (o de la llamada neoescolástica [A. G. Weiler]) al decir que es la Discreción/Prudencia la que debe regir al individuo evitando que pueda caer en la pasión del amor vicioso que termina con la libertad humana, condenándole a la prisión de la pérdida de su mente, su frónesis (T. Potts, R. Saarinen, D. Westberg). Permítaseme que en este punto introduzca una cita larga sobre lo que ya apunté al respecto de la coincidencia entre De amicitia (de Boncompagno da Signa) y el Siervo, para entender la perspectiva de que parten Mena/Núñez:

Las dos obras (De amicitia, Siervo libre de Amor, a su vez parecen acabar girando sobre una discusión sobre el discernimiento racional, la conciencia, la prudencia y la práctica de la virtud, con un énfasis en el amor humano irracional (concupiscible) y la superación de la fantasmagoría del mismo, insistiendo sobre la capacidad racional humana de discernir el bien sobre el mal y de aplicarla adecuadamente a circunstancias concretas (amorosas) con la ejercitación de la virtud. Si De amicitia, como hemos indicado, se basa en una elaboración de la Ética a Nicómaco (libro VIII), no debemos olvidar que la reflexión fundamental de santo Tomás sobre Sindéresis - donde se lee el tratamiento medieval más elaborado sobre la misma- se basa a su vez en una relectura de la Ética a Nicómaco (libro VII, 3). Allí Aristóteles propone que aunque uno tenga "en hábito" el conocimiento de que debe evitar fornicar con una mujer soltera, su deseo de hacerlo se le representa como una "cegazón" que le hace ver "en acto" la fornicación como perteneciente a la esfera del placer (pues lo placentero debe perseguirse). Es, pues, no el conocimiento del universal sino la evaluación de lo sensible lo que queda defectuoso, motivado como está por la pasión. El hombre incontinente -dice ahora el Aquinate-- fracasa en la aplicación de su conocimiento del principio universal a la circunstancia concreta porque no ha cultivado las virtudes que le deberían haber ayudado a analizar apropiadamente la situación y deliberar al respecto sobre ella. Es decir, santo Tomás pone en uno la conciencia, la prudencia y las virtudes en su relación con la debilidad de la voluntad o "aprisionamiento" de la misma. Sindéresis se encarga de reconocer principios primarios (muy generales) de 
comportamiento. Pero para poder aplicarlos a circunstancias concretas la conciencia necesita explicitar mucho más estos primeros principios, creando principios secundarios. Estos principios secundarios se derivan de la experiencia y de la instrucción o aprendizaje mediante la virtud de la prudencia, que es quien se encarga de aplicar a circunstancias concretas y particulares estos principios primeros. De este modo la prudencia es quien conecta la conciencia al problema de la debilidad de la voluntad. El amor, como dice Boncompagno, no existe sin amistad y "la amistad no puede operar sin la discreción de la razón”, es decir, sin el ejercicio de la vis cogitativa (o ratio particularis). Aunque en puridad Discreción y Sindéresis no son lo mismo, no debemos olvidar que en ambas obras (De amicitia, Siervo libre de Amor) las dos ejercen la misma función de "recuperadoras" de la racionalidad tras un período de "irracionalidad" en lo que toca a la distinción entre el bien y el mal (amor) en las circunstancias concretas de aplicación práctica (praxis) de la razón. Es decir, estamos ante una discusión sobre el amor concupiscible que "ciega" la razón en el ejercicio práctico de la vis cogitativa. (A. Cortijo 2006)

Llegados a este punto se le impone a Mena/Núñez la resolución del conflicto aparentemente no dilucidable que ha ido construyendo en las coplas precedentes. Definido el amor vicioso como un furor que ciega, pasional y no deleitoso, ha hablado asimismo, a través del ejemplo de Macías, de una pasión superior al "retraimiento" voluntario, aunque la condena de los amadores sea consecuencia de su falta de prudencia y discreción. Lo necesario del fenómeno amoroso no parece, pues, en esta argumentación, darse la mano fácilmente con su inescapabilidad. A partir del comentario a $110 \mathrm{ab}$ Núñez intenta una respuesta:

Avía preguntado el poeta a la Providencia la causa por que los que ha dicho que vio en este cerco, como fuessen prudentes y sabios, se quisieron amar ciegamente. Responde en esta copla la Providencia, y lo que quiere dezir es que como el amor no sea cosa artificial syno natural, no va en mano de los hombres poderlo evitar por más prudencia y saber que tengan, porque si se causasse el amor o por palabras de encantaderas, o por hechizerías o por medicamentos y virtudes de yervas o piedras, podría aver para él alguna resistencia. Pero como se cause por naturaleza, si el amor es verdadero, no fácilmente se puede apartar dél [..] Así que no preguntó bien el poeta en dezir 'por qué quisieron amar ciegamente', quasi oviese sido en su mano huyr el amor, y que las encantaciones o hechizerías no puedan causar amor en el que de su naturaleza no lo tiene (110ab)

Núñez responde así a dos de los temas de mayor calado entre los comentaristas filosóficos de la época, como Alfonso de Madrigal, el Tostado, o como el autor (¿anónimo?) del tratado De cómo al omne es neçesario amar (A. Cortijo [2001], P. Cátedra), que -en clave de lectura quizá un tanto bufa de Aristóteles- proclama que el amor hacia mujer plazentera no debe escaparse o huirse, pues no hay nada más justificado en y por la naturaleza que dicho impulso a amar. Aquí Núñez no parece en absoluto darse a bufonada alguna, o a regusto burlesco propio del ambiente paródico de las disputationes estudianteles, sino expresa sin mayor intención escondida que el 
amor se da en la naturaleza, es decir la atracción física entre hombre y mujer, entre macho y hembra. En segundo término, responde Núñez a otro debate del momento sobre la categoría de la magia, a su vez inserto en el de la entidad de la astrología y el influjo de las estrellas en la voluntad humana (recuérdese el afamado caso de Enrique de Villena y Lope de Barrientos) y la determinación que pueden aquéllas ejercer sobre la conducta individual. Dice al respecto, salvaguardando así lo que es creencia indisputable del humanismo cristiano, que la capacidad libre de tomar decisiones le es propia al hombre y que, por ende, el intento de influenciarla o dominarla por parte de la magia queda siempre supeditado al libre ejercicio de la voluntad, siempre y cuando los hombres "fuesen prudentes y sabios". Los efectos de la magia, quiere decir, deben achacarse al individuo que los sufre, por debilidad (moral y volitiva), y no a la posibilidad (que no es tal) de que alguien puede en puridad alterar el ordo naturalis. Recuerda al respecto de las "hechizerías [...] de las malas mujeres o hombres que las tales artes usan" el uso de hippomanes, carnecilla pequeña o telilla de los potricos recién nacidos", así como una "imagen de cera semejante a la persona que quieren atormentar", hincada con agujas; y "rombos" o instrumentos de hilos de alambre, la yedra, etc. Magia y amor, así, como ocurrirá en ese texto literario antológico que es La Celestina, se dan indisociablemente la mano en cuanto toca al ejercicio de la libertad volitiva humana, de la capacidad de decidir y de la proclamación de la inexistencia del predeterminismo sobre el individuo, digna criatura de Dios. Macías, no obstante, es un exemplum que conlleva cierta ambigüedad, cierto regusto a inexcrutabilidad. Si bien no se duda de su sinceridad, de la autenticidad de su sentimiento amoroso, si bien se le elogia por su perseverancia amorosa en buena lid ovidiana, tampoco se ignoran nunca en el recuento de su historia las consecuencias catastróficas de dicho amor, ya sea para él mismo, ya lo sean para su enamorada y esposo, ya incluso para el rey. Lamentablemente para Macías su amor no existe in vacuo sino dentro de unas muy marcadas coordenadas de tiempo y lugar, contexto social en el que observar las consecuencias de su amor frustrado. Pero los comentaristas, y Núñez con ellos, también perciben un algo superior al poeta mismo en la historia de Macías, algo que escapa cualquier clasificación o intento de comprensión. Es la imposibilidad del vate gallego de detener su sentimiento, la incapacidad de domar su pasión. Porque esta imposibilidad se presenta como un reto a la explicación humanista, que, aun salvaguardando a toda costa la sacrosanta libertad humana, debe vérselas con lo que parece ser una fuente pasional que rinde impotente al individuo. De la oposición entre un potens como característica sine qua non del ser humano y el impotens del caso Macías surge un misterio que presta si cabe mayor hondura trágica al gallego y le da casi una aureola de santidad ${ }^{1}$.

${ }^{1}$ A Macías se le podría pedir, en puridad, que hubiera acabado su periplo como el protagonista del Siervo libre de Amor, que acaba siendo rescatado por Sindéresis. "El yonarrador concluye su periplo amoroso (su viaje vital) tras haber llegado a la recuperación del juicio después de haberlo perdido. Se trata de un lugar interno de reflexión, consolación y hasta autoconfesión, desde el que el yo-narrador se sincera consigo mismo y con su audiencia lectora" (A. Cortijo [2007]). 
Pero Núñez no quiere dejar cabos sueltos en su argumentación. Tras el discurso vituperativo sobre lo que es condenable y ha de evitarse en la conducta amorosa, como conducente al vicio y al aniquilamiento o rendición de la voluntad, Núñez comenta, de modo elogioso, las cuatro cosas "que juntan y allegan las voluntades de las personas para que quieran bien a otros" (111a). Sigue en ello, claro está, el esquema que ya dejara sentado Ovidio y que pasa de los Amores a los Remedia amoris y que no son dos gradaciones del amor sino sus dos caras alternativas. En gradatio ascendente, y en lo que toca al sexo femenino, dice, existen cuatro características "que impellen al hombre a amar la mujer: la hermosura, el linaje, las riquezas, las virtudes y buenas costumbres". Y en clave misógina que ve a la mujer como engañadora y experta en blanditiae, refrendada por los textos y conceptos de Séneca o Juvenal y de la patrística, añade que "las dádivas $[\ldots]$ ciegan mucho a los hombres y son impedimento para la recta conciencia", así como que "las palabras dulces y blandas de las mujeres son grande anzuelo para pescar las voluntades de los ombres".

El comentario a la estrofa 112 insiste en otro tópico de la literatura de amore cuatrocentista, el debate sobre los casus amoris expresados en clave de debate deliberativo, que llegará al siguiente siglo en obras como las Églogas de Garcilaso, entre otras, y que ya en el siglo XV constituyen un componenente imprescindible de casi todos los textos del género de la novela sentimental (A. Cortijo [2001]). El que primero ama obliga al objeto de su amor a reciprocar; algunos hay que, sabiéndose amados, "no pagan en el mismo amor;" entre estos últimos, los que hay que incluso aborrecen a quien los quiere, conducta la más reprobable entre todas. Causística, en suma, de poca relevancia para el tema tratado, y que, abordada por Mena, Núñez no se demora mucho en comentar.

En la copla siguiente se recupera el tema anterior de la Discreción/Prudencia, de nuevo comentando el tema del amor ante el que nada se puede, del amor supra voluntatem. "La discreción", dice, "non basta para apartarse del amor, quando el que le tiene le tiene verdadero, non ficto". Y recogiendo unas palabras de Ausonio, porque el amante así obsesionado pierde su capacidad racional, llama al mismo "amente, que significa loco sin seso" (113c). Pues quien así se aparte de su mens pierde la capacidad de la phrónesis, "se desenfrena", o pierde la temperantia (templanza). El uso prudente del intelecto, la reflexión sopesada y discreta, el uso de los casus amoris como exempla de los que aprender y con los que dilucidar, así como el ejercicio de la Sindéresis para tomar una decisión última sobre la acción moral del individuo, todo ello supone el ejercicio de una mediocritas como ideal de vida, que en el caso del amor debe regirse por la temperantia, la templancia quieta que evita la pasión que enardece, el fuego que destruye sin cauterizar.

El amor, como ha ido exponiendo Hernán Núñez, se trata en el círculo de Venus como un proceso, un acto, una conducta criminosa que conduce al sufrimiento, entendido - por encima de su sentido cristiano dentro del esquema de la salvación- como pena, castigo o condena dentro del edificio argumental del Laberinto de Fortuna. Este amor adopta a lo largo del comentario diferentes variedades y subtemas, que pueden hasta cierto punto entenderse como una 
casuística amorosa o un conjunto de casus amoris. Pero algo por encima de esta tipología parece dar sentido a la construcción expositiva de Hernán Núñez. Quizá recurriendo al análisis filosófico griego de eros, tamizado luego por los escritos patrísticos (de san Agustín y san Jerónimo entre otros [ver L. D. Reynolds, H. Pabel, J. Bentley, D. Cantimori, Ch. Stinger y E. Rice]), el comentarista establece en su análisis del amor los diferentes registros y variedades del mismo, que son esferas de aplicación erótica del amor al ser humano en sus posibles facetas vitales. Así, el amor/eros tiene un campo de aplicación que concierne al individuo y que le afecta en cuanto ser individual, ser moral. Dotado de una dignidad como tal, cuando se somete a un sentimiento amoroso convertido en pasión destructora pierde su capacidad de frónesis, anula su mente, su conducta no se regula por la prudencia o la discreción, y por ende se convierte en un amente, preso y encarcelado en sí mismo. Podría decirse, en conclusión, que se desprende conscientemente de su dignidad humana. Existe asimismo en el amor una dimensión filial (filia), que establece una relación especial entre seres en donde el componente erótico (sexual) no existe, y que se define en el comentario como una concordia voluptatum. Es un ideal que oponer a la luxuria previa y que aparecerá privilegiado en la literatura del humanismo tanto cuatrocentista como quinientista. Esta concordia crea un nexo re-ligioso, una atadura que insiste en lo que de comunitario porta el ser humano, que alcanza su realización última a través de procesos relacionales que le sacan de su individualismo y que se enfoca en las relaciones de concordia entre esposos, entre amigos (yo-tú) o entre grupos que el mundo griego llama conviviales. Núñez dedica amplio espacio al análisis de una tercera faceta del amor, una que podríamos denominar social. Si la amistad como desideratum insiste en lo positivo del amor como sentimiento, ahora se insiste en el poder destructivo del amor en lo que toca a la fábrica social (agapé y polis). Macías es quizá representante ilustre de este punto. La obligatoriedad de su amor, su pérdida de capacidad discrecional y la fuerza del furor amoroso convertido en obsesión imparable están lejos de tener solo repercusiones para él mismo. Su enamorada, el esposo de ésta y el rey quedan todos afectados por un comportamiento insocial que rompe la quies y engendra un bellum que solo puede producir un caos que conduce a la muerte. La tragedia de Macías no radica en la perseverancia loca en un amor inmarcesible, ni siquiera en el furor porfiado de su amor cortés, sino en la imposibilidad de pararlo a la vista de las consecuencias de destrucción social (amén de personal) que el poeta ve crearse a su alrededor. A este mismo campo político pertenece, con matiz distinto, el comentario final del Hernán Núñez (114a et ss.). Dirigiendo ahora Mena su discurso al rey, le amonesta para que vele por los "peligros y daños" (sociales, políticos) que nacen del amor no limpio y le insta a que "constriña" a sus súbditos al matrimonio. En este alegato al ejercicio de la justicia real le pide asimismo (con base en la literatura patrística) que modere su actuación con clemencia y misericordia, virtudes paralelas y atributo respectivamente de la magestad y la divinidad. Núñez realza este punto en su comentario al pasaje al usar como fuentes autores y ejemplos grecorromanos pertenecientes al mundo histórico-jurídico como Dracón, 
Flavio Vopisco, Vulcacio Galicano o Trebelio Polión (ver Adelaida Cortijo, R. Sánchez de Arévalo y J. Weiss). Las dos virtudes, curiosamente, son ejemplo de amor a un nivel máximo, superior, en relación con la última faceta del amor, la charistía. No se trata ahora de analizar los efectos amorosos por encima del nivel individual y dentro del orden sociopolítico/comunitario, sino en el nivel de la comunión especial entre Dios y las criaturas, una ligatio última que adopta tonos religiosos si se entiende como una re-ligio/religión. Aquí correspondería el discurso sobre la hechicería. La misma no solo se reprueba por intentar perturbar la voluntad humana (se escapa a ello el individuo ejerciendo en todo punto la discreción y prudencia) y destruir el orden social, sino es por encima de ello un intento de pervertir la naturaleza, arrogándose un papel que solo a Dios corresponde y por ende asociándose con el antagonista divino por excelencia, el Demonio.

El amor, primero vislumbrado como un deseo sexual, natural, va infundiendo su esencia por todo el ser humano al completo, en todas y cada una de sus facetas. $\mathrm{Y}$ ellas se presentan en un todo unitario, ascendente, progresivo, que avanza desde la satisfacción básica de los instintos, con su extremismo lujurioso, a la creación de nexos de amistad y cohesión social y con la Divinidad. Y en estos últimos pueden asimismo alcanzarse extremos caóticos que se salen del ideal de la moderación, el medio, la mediocritas. Pasan desde la obsesión personal e individual al egoísmo social y el intento de suplantación del poder divino queriendo anular la libertad humana. Todo ello, pues, es amor, todo ello igualmente es desamor si se extrema y desequilibra, con sus funestas, destructoras $\mathrm{y}$ atroces consecuencias.

Núñez (J. de Mena) aborda así un panorama erótico completo en su expositio y commentarium. Amor, término latino ambiguo o multifacético si se quiere, se explica en sus diferentes manifestaciones de eros, filía, agapé y charistía. El amor venusino ("luxuria", "fuego de la diosa Venus", 114f) atenta contra la creación divina, y lo hace destruyendo los órdenes en que el individuo manifiesta su dignidad y existencia. De hecho san Isidoro deja sentada la opinión de que "no ay otro peccado que tantas ánimas ni por tantas maneras lleve al infierno como la luxuria" (109a). Si el amor es ante todo ligatio, unión, atadura, concordia y quies, la pasión amorosa es una exageración del mismo que obsesiona, enfurece y destruye. Acaba con el individuo como ser racional, reducido a una irracionalidad animal que le desprovee de dignidad como ser humano y le reduce a instinto, indiscreción, imprudencia; y el caos personal engrendrado se trasmite en línea ascendente al mundo social y político en que el hombre debe cumplir su existencia. La ligatio pacífica moderada por el equilibrio, prudencia y quies, se convierte en un chaos bélico. Y por encima de todo(s) este(os) tipo(s) de amor(es), y también como en el caso del Siervo libre de Amor, queda la iluminación divina amorosa que hace que el hombre desee y se deleite con su Criador.

Pero Mena no quiere terminar aquí su descripción del tercer círculo, pesimista en exceso sobre el poder del amor lascivo ("Después que en esta tercera orden de 
Venus ha tratado de los que fueron dados al amor, pone agora convenientemente la diffinición del amor y declara qué cosa es."). Y así la concluye con una definición del amor (positivo) en que la destrucción (bellum) se sublima en corcordia, la pasión en afecto, la destrucción y condena en gozo y deleite. Núñez, humanista cristiano que hace uso del commentarium para exponer los saberes humanos con exhaustividad y que en el proceso construye un edificio que gira en torno al hombre definido según ideal humanista por su dignidad, no puede en buena lógica hacer una exposición sistemática del amor dejando en el lector un regusto de desolación, privación de libertad, ruina y calamidad. La última estrofa comentada, loa que queda resonando en la mente del lector, es un canto al amor, una especie de epinicio erótico en que el amor, dejando de ser fuerza destructiva, se convierte, como Cristo, en fons vitae, en fuente de vida.
Copla cxv
Diffinición del amor
El qual es tal medio de dos coraçones, que la voluntad, que estava no junta, la su dulcedumbre concorda y ayunta, haziéndoles una sus dos opiniones, y dando tal parte de sus affectiones: a los amadores, sin gozo, cadena, y a los amados, deleyte sin pena a los menos méritos, más galardones.

En el comentario a esta estrofa Núñez recalca esta fuerza unitiva del amor, casi expresada en términos místicos. Primero ataca sin cuartel a Venus, Cupido y el dios Amor, "prepósteros y mal ordenados," porque reparten mal entre sus seguidores sin dar a cada uno lo suyo (suum cuique tribuere, base del sistema judicial y de la fábrica social bien comnstituida), no dando galardón a quien lo merece y a quien lo merece dándole pena. El amor verdadero, por el contrario, y que imaginamos que es tanto un amor entre individuos como en su aspecto social y religioso (amor Dei), es creativo. Su esencia es unitiva y frente al caos produce una comunión de almas:

Los que antes estavan apartados en diversos quereres y tenían diversas voluntades, interviniendo el Amor se hazen tan semejantes que todos sus affectos se tornan unos. (115e)

Venus, en suma, pasa en el comentario de Núñez de dea vituperanda a dea veneranda. El humanismo cristiano del comentarista necesita superar las construcciones clásicas y paganas del dios Amor y de Cupido, atentos a procurar placer y deleite exclusivamente. Con su centro en la psicología y filosofía natural tomistas, aquéllos solo satisfacen las pasiones humanas, que, desmesuradas, conducen a la tragedia personal del desequilibrio (ejemplificada por el caso de Macías) y la obsesión que anula el ejercicio de la libre voluntad moderada por la 
prudencia. Mas si Cupido y el dios Amor quedan superados en el esquema de Núñez es porque el amor ciego que representan queda superado por el amor liberador y salvífico representado por quien, en puridad cristiana y novotestamentaria, es caridad. El ser humano ha nacido para amar, es el corolario de la exposición del comentarista Núñez, para la comunión entre los hombres, ya sea de carácter filial, comunitaria, social o política. El amor deseable no es, pues, tragedia sino concordia, comunión de corazones, unión de voluntades en el libre ejercicio de su volición. Este planteamiento es en esencia el de un humanismo cristiano que retoma los temas predilectos de la patrística y, con el aderezo de la filosofía tomista, les da un ser nuevo en el programa reciente del umanesimo. Éste pone el énfasis en la criatura, en el hombre como ente pensante, como ente libre, como ente volitivo, cuya capacidad de aprender (y leer) supone un ejercicio de su intelecto, que le aúpa por encima de todos los demás seres de la creación. Ítem más, este ejercicio de la mente en libertad creadora y de decisión asemeja al hombre con el Dios que le crea, pues la criatura humana también es creadora a través de su producción intelectual y producción amorosa. Y el énfasis en la criatura no se circunscribe al plano exclusivamente moral e individual, sino que lo trasciende para situar al humanista (ejemplo máximo de ser humano) en el centro de un sistema social ideal, en que el hombre enseñado, estudioso y recto moralmente sirve de modelo para la actuación, dispuestos los componentes sociales y personales en perfecta armonía en el edificio de la sociedad de los hombres. El fin último de este esquema es lograr la realización plena del ser creador en los planos yuxtapuestos individual y social, modelados sobre el ideal de la quietud y la paz, sobre una moderación sabia agena a extremos desequilibrantes y a conflictos intersociales. Y es precisamente esta quies, esta pacífica tranquilidad en el reposo del equilibrio entre las partes a la que podemos, con Núñez, llamar amor. Un amor que se ha desprovisto del furor pasional y se ha remansado en anhelo de unión, comunión, (re)ligión. Este edificio humanista, un a modo de plano maestro sobre el que erigir construcciones concretas, tiene como piedra maestra de su arco, sobre el que todo se sustenta, al hombre. Un hombre, claro está, creado a imagen y semejanza de la divinidad y que, en buena lógica, debe aspirar a trascender --luego de lograr el amor terreno, así entendido-- el amor mundi con un deleitoso amor Dei. Pues como se encargará de explicar la mística humanista de raigambre platónica, el anhelo máximo del individuo está en subsumirse en la totalidad amorosa de la divinidad, hecho uno con la misma, aunque manteniendo -a toda costa para un humanista- la voluntad intransferible del ser humano. Y este ideal de quietud, de supresión o aniquilación de la pasión, es --en imagen dantesca-- equivalente a la inefabilidad (conclusión de la paz, la tranquilidad, la quietud) que produce la visión directa de la gloria de Dios, suprema superación como Deus Amoris de la Venus lujuriosa cuyos seguidores pueblan el trágico círculo tercero de Mena. Aunque este último plano, si se quiere religioso o 'cristiano' (ver V. García de la Concha), queda, como en todo el comentario de Núñez, en un respetuoso trasfondo. Pues Amor se aplica para el de Toledo a un ser humano dignificado que vive siempre en el aquí y ahora, a un ser 
humano que aupado a un puesto central en la creación es casi el protagonista central (sujeto de educación, de lectura, de conducta virtuosa y moral, de aprendizaje, de ejercicio político, etc.) de todo el comentario de Núñez ${ }^{2}$.

\section{OBRAS CITADAS}

BENTLEY, Jerry H.: Humanists and Holy Writ: New Testament Scholarship in the Renaissance, Princeton, Princeton UP, 1983.

CARAVAGGI, G.: Alle origini del petrarchismo in Spagna, Pisa, Instituto di Lengua e Letteratura Spagnola dell'Università di Pisa, 1971-1973.

CÁTEDRA, Pedro: Amor y pedagogía en la Edad Media, Salamanca, Universidad de Salamanca, 1989.

CANTIMORI, D.: Humanismo y religiones en el Renacimiento, Barcelona, Península, 1984.

CORTIJO OCAÑA, Adelaida: "Teoría política y poder en la literatura medieval castellana (ss. XII-XV)", Diss. University of California, Berkeley, 2005.

CORTIJO OCAÑA, Antonio: La evolución genérica de la ficción sentimental, Londres, Tamesis, 2001.

---: "Notas sobre El Tostado de amore," En R. Recio \& A. Cortijo eds., "Critical Cluster. El Tostado", La Corónica, 33.1 (2004), pp. 67-85.

---: "De amicitia, amore et rationis discretione. Breves notas a propósito de Boncompagno da Signa y el Siervo libre de Amor", Revista de Poética Medieval, 16 (2006), pp. 23-52.

---: "El Siervo libre de Amor y Petrarca. A propósito del motivo de la nave", Revista de Poética Medieval, 18 (2007), pp. 133-154.

CORTIJO OCAÑA, Antonio, \& Julian WEISS: "El Sermón de la Sagrada Escritura de Pseudo (Agustín) y la versión romance de Hernán Núñez. Notas sobre el humanismo cristiano del primer Renacimiento", La Corónica, 31:7 (2008), pp. 145-74.

DÍEZ FERNÁNDEZ, J. Ignacio: La poesía erótica de los Siglos de Oro, Madrid, Laberinto, 2003.

FOLGER, Robert: Images in Mind. Lovesickness, Spanish Sentimental Fiction \& Don Quijote, Chapel Hill, UP, 2002.

${ }^{2}$ Aunque se sale fuera del propósito de estas notas centradas en el comentario mismo de Núñez, no podemos cerrarlas sin mencionar que el comentarista sigue un esquema sobre el tema amoroso creado por Juan de Mena, cuyo poema comenta. A Núñez corresponde adobarlo con las fuentes patrísticas y clásicas de muchos pasajes, algunas conocidas por Mena mismo, la mayor parte no, así como situarlo en un esquema de explicación de las facetas del ser humano, por todo lo largo de su amplísima obra de comentario o glosa a las Trescientas. Pero no estaría de más dejar cuando menos mencionado que el pre-renacentismo (M. R. Lida de Malkiel, J. Lawrance, F. Rico) de Mena vislumbra muchos de los aspectos que luego Núñez se encarga de construir de modo erudito, didáctico y -particularmente- totalizador y sistemático. 
GARCÍA DE LA CONCHA, Víctor: "La impostación religiosa de la reforma humanística en España: Nebrija y los poetas cristianos", En Nebrija y la introducción del renacimiento en España, Salamanca, Universidad, 1983, pp. 12343.

JIMÉNEZ CALVENTE, Teresa: "Virgilio y sus comentaristas renacentistas (I)", Estudios Clásicos, 120 (2001), pp. 35-64.

---: "Los comentarios a las Trescientas de Juan de Mena", Revista de Filología Española, 72 (2002), pp. 21-44.

LAWRANCE, Jeremy N. H.: "Humanism in the Iberian Peninsula," EnThe Impact of Humanism on Western Europe, London, Longman, 1990, pp. 220-58.

LIDA DE MALKIEL, María Rosa: Juan de Mena: Poeta del prerrenacimiento español, México, D.F., El Colegio de México, 1984 [1950].

MENA, Juan de. Ángel Gómez Moreno \& Teresa Jiménez Calvente eds., Obra completa, Madrid, Turner, 1994.

NADER, Helen: “'The Greek Commander’ Hernán Núñez de Toledo”, Renaissance Quarterly, 31 (1978), pp. 463-85.

NAVARRETE, Ignacio: Orphans of Petrarch, Bderkeley, Los Angeles, U California Press, 1994.

NUÑEZ DE TOLEDO, Hernán: Las Trescientas del famosissimo poeta Juan de Mena con glosa, Sevilla, Johann Pegnitzer von Nürnberg et al., 1499.

---: Trescientas del famosissimo poeta Juan de Mena con glosa, Granada, Juan Varela, 1505.

---: Julian Weiss \& Antonio Cortijo eds., Comentario a las 'Trescientas' de Hernán Núñez de Toledo, el Comendador Griego (1499, 1505), eHumanista (www.ehumanista.ucsb.edu) (projects).

PABEL, Hilmar M.: "Reading Jerome in the Renaissance: Erasmus' Reception of the Adversus Jovinianum", Renaissance Quarterly, 55 (2002), pp. 470-497.

POTTS, Timothy: Consciente in medieval Philosophy, Cambridge, Cambridge University Press, 1980.

REYNOLDS, L.D., \& N.G. WILSON: Scribes and Scholars: A Guide to the Transmission of Greek and Latin Literature, Oxford: Clarendon, 1974 [1968].

RICE, Eugene F.: Saint Jerome in the Renaissance, Baltimore, Johns Hopkins UP, 1985.

RICO, Francisco: El sueño del humanismo, Madrid, Alianza, 1993.

SAARINEN, Risto: Weakness of the Will in Medieval Thought from Augustine to Buridan, Leiden, New York, Brill, 1994.

SÁNCHEZ DE ARÉVALO, Rodrigo: Spejo de la vida humana, Zaragoza, Pablo Hurus, 1491 (Adelaida CORTIJO OCAÑA ed.: Admyte 3 (Archivo Digital de Manuscritos y Textos Españoles), en prensa).

STINGER, Charles L.: Humanism and the Church Fathers: Ambrogio Traversari (1386-1439) and Christian Antiquity in the Italian Renaissance, Albany, SUNY Press, 1977.

WEILER, A.G.: "Humanisme et Scolastique: le renouveau de la pensée chrétienne à la Renaissance", Concilium (Revue Internationale de Theologie), 27 (1967), pp. 29-43 
WEINBERG, Bernard: A History of Literary Criticism in the Italian Renaissance, Chicago, U of Chicago P, 1961.

WEISS, Julian: "Political Commentary: Hernán Núñez's Glosa a "Las trescientas", en Letters and Society in Fifteenth-Century Spain: Studies Presented to P. E. Russell on his Eightieth Birthday, Llangrannog, UK, Dolphin, 1993, pp. 205-16.

WESTBERG, D.: Right Practical Reason, Oxford, Clarendon Press, 1994.

WHINNOM, Keith: La poesía amatoria cancioneril en la época de los Reyes Católicos, Durham: University of Durham, 1981. 